\title{
DISPOSIÇÃO (IR)RESPONSÁVEL DE RESÍDUOS SÓLIDOS URBANOS NO ESTADO DO CEARÁ: DESAFIOS PARA ALCANÇAR A CONFORMIDADE LEGAL
}

\author{
Gleison Mendonça Diniz \\ Doutor em Administração de Empresas \\ Tribunal de Contas do Estado do Ceará \\ Fortaleza - Ceará - Brasil \\ gleison.diniz@tce.ce.gov.br \\ Mônica Cavalcanti Sá de Abreu \\ Doutor em Engenharia da Produção \\ Universidade Federal do Ceará \\ Fortaleza - Ceará - Brasil \\ mabreu@ufc.br
}

\section{RESUMO}

O objetivo do trabalho é avaliar os desafios para atender as exigências legais definidas nas Políticas Nacional e Estadual de Resíduos Sólidos, no Estado do Ceará. A pesquisa é de natureza quantitativa e foi realizada por uma coleta de dados obtida por meio de formulário aplicado aos gestores das secretarias municipais de meio ambiente. Os dados foram tratados por meio de estatística descritiva e análise de clusters. Contrariando-se as exigências normativas, os resultados da pesquisa demonstram a ausência de um adequado tratamento dos resíduos sólidos gerados nos municípios do estado do Ceará. Essa pesquisa aponta ainda, que o lixão é, predominantemente, o destino final dos resíduos sólidos; que não existe controle da quantidade de resíduos gerados; parte da área destinada aos resíduos sólidos é praticamente de livre acesso e existe uma baixa participação de catadores na reciclagem de resíduos. De forma preocupante, a maior parte dos municípios do Ceará ainda encaminha seus resíduos hospitalares aos lixões. Esse trabalho conclui que a conformidade legal decorre de um esforço mútuo entre os órgãos da administração pública, a iniciativa privada e a sociedade, na implantação de um gerenciamento de resíduos sólidos, capaz de reduzir a degradação ambiental e as desigualdades sociais.

Palavras-chave: Gestão ambiental; Política estadual de resíduos sólidos; Política nacional de resíduos sólidos; Resíduos sólidos.

\section{URBAN SOLID WASTE (IR) RESPONSIBLE DISPOSAL IN THE STATE OF CEARÁ: CHALLENGES TO ACHIEVE LEGAL COMPLIANCE}

\section{ABSTRACT}

The paper analyzes the disposal of solid waste in the cities of the state of Ceará, evaluating the fulfillment of requirements of the National and State Policies of Solid Waste. This is a quantitative research and was carried out through a data collection obtained with a form application to managers of the municipal environmental departments, evaluating the fulfillment of requirements of the National and State Policies of Solid Waste. Data were analyzed using clusters analysis technique. Contrary to regulatory requirements, the results demonstrate the absence of a treatment of solid waste generated in Ceará. The results revealed that, predominantly, the dumping ground is the final destination of solid waste; there is no control of the amount of waste generated and a part of the area destined to solid waste is practically out of access. The majority of municipalities in Ceará state still send their medical waste to the garbage dumps. The research concludes that the municipalities in Ceará do not fulfill legal requirements and reinforce the mutual efforts including government, companies and society in order to establish a solid waste management to reduce environmental degradation and social differences.

Key words: Environmental management; National solid waste policy; Solid waste; State solid waste policy. 


\section{INTRODUÇÃO}

A municipalização de políticas públicas caracteriza-se como uma forma de descentralização administrativa dos mecanismos e políticas de intervenção federal (Garcia e Diniz, 2016). Jucá et al. (2014) ilustram que o gerenciamento dos resíduos sólidos urbanos constitui responsabilidade da administração municipal e envolve uma sequência de atividades que contribuem com a melhoria do sistema de limpeza urbana. Estas atividades abrangem a redução, reutilização e reciclagem (3R); o acondicionamento; a coleta e transporte dos resíduos; a limpeza dos logradouros; o tratamento (e.g., compostagem, reciclagem, digestão anaeróbia, e incineração) e a disposição final.

Entre os anos de 2000 e 2008, Gouveia (2012) mostrou que houve um aumento de 36,2\% para 64,6\% na quantidade diária de resíduos sólidos, domiciliares e/ou públicos, coletados e/ou recebidos nos aterros sanitários. Ocorreu ainda uma discreta diminuição da disposição dos resíduos sólidos em lixões. Além de pequenas variações para outras destinações dos resíduos sólidos urbanos, como a compostagem, incineração e reciclagem.

Na perspectiva de um desenvolvimento sustentável, impõe-se a necessidade de implantação de uma gestão ambiental pública que garanta a disposição responsável de resíduos sólidos. Isto significa atender aos requisitos legais instituídos nas Políticas Nacional e Estadual de Resíduos Sólidos, como forma de preservar o meio ambiente e garantir a saúde pública.

A Lei $\mathrm{n}^{\circ}$ 12.305, aprovada em 2 de agosto de 2010, instituiu a Política Nacional de Resíduos Sólidos (PNRS), com a previsão de implantação de programas de prevenção da poluição, de redução da geração de resíduos e de incentivo ao consumo sustentável. Definiu também instrumentos capazes de ampliar a reciclagem e reutilização dos resíduos sólidos, além da destinação ambientalmente responsável (Brasil, 2010). Especificamente, o art. $9^{\circ}$ elucida que, no gerenciamento de resíduos sólidos, deve ser observada a seguinte ordem de prioridade: não geração, redução, reutilização, reciclagem, tratamento dos resíduos sólidos e disposição final.

No estado do Ceará, a Política Estadual de Resíduos Sólidos (Pers) foi estabelecida pela Lei $\mathrm{n}^{\mathrm{o}}$ 13.103, aprovada em 24 de janeiro de 2001. O art. 5º nos seus incisos V e VI, exige a implantação de sistemas de tratamento e disposição final de resíduos sólidos, assegurando a utilização adequada e racional dos recursos naturais e preservando-os para as gerações presente e futura. Esta lei trata também da promoção, da recuperação das áreas degradadas ou contaminadas em razão de acidentes ambientais (Ceará, 2001).

Contudo, existem dificuldades para realizar uma eficiente gestão ambiental pública. Abreu, Mesquita e Silva Filho (2014) identificaram que as dificuldades se relacionam com a falta de planejamento ambiental dos municípios, a ausência de recursos financeiros, a baixa capacitação técnica e o desconhecimento da legislação e dos instrumentos de gestão ambiental. No entendimento de Giesta (2013), a gestão ambiental pública precisa ser implementada com o acompanhamento de uma série de mudanças no ambiente institucional.

A partir dessas considerações, levantou-se o seguinte problema de pesquisa: Em que extensão os municípios do estado do Ceará atendem aos requisitos das Políticas Nacional e Estadual de Resíduos Sólidos? O objetivo da pesquisa consiste em avaliar os desafios impostos aos gestores públicos para alcançar a conformidade legal. Com o apoio de técnicas multivariadas de dados, o trabalho contribui com a gestão ambiental pública, na medida em que apresenta um panorama dos locais de destinação dos resíduos sólidos, da presença de catadores nos municípios e do tratamento dos resíduos hospitalares.

Para atingir o objetivo proposto, a próxima seção aborda os aspectos legais da gestão de resíduos sólidos urbanos e seus desafios relacionados aos municípios para alcançarem a conformidade legal. Em seguida, são apresentados a metodologia da pesquisa quantitativa e os resultados encontrados. Por fim, o estudo mostra um panorama preocupante dos municípios cearenses com relação à disposição de resíduos sólidos urbanos. 


\section{ASPECTOS LEGAIS DA GESTÃO DE RESÍDUOS SÓLIDOS URBANOS}

Khan e Ansari (2010) definem o termo "resíduos sólidos urbanos" como oriundos de residências, ruas, praças, lojas, escritórios e hospitais. A responsabilidade da disposição final pertence às autoridades municipais e estaduais. Pillai e Shah (2014) apontam as principais razões para o aumento da geração de resíduos sólidos: o crescimento populacional, a rápida urbanização, o aumento da renda e do consumo.

Neste sentido, a gestão de resíduos sólidos pode ser definida como a administração sistemática de atividades que envolvem a separação, o armazenamento, a coleta, o transporte, a transferência, o processamento, o tratamento e a disposição final dos resíduos. Esta gestão visa reduzir a quantidade descartada, por meio da recuperação de materiais ou da geração de energia. Padrões e normas para o manejo de resíduos sólidos urbanos podem minimizar substancialmente os impactos negativos sobre a saúde da população. A coleta seletiva, com inclusão de catadores de materiais recicláveis, e a recuperação de energia e reaproveitamento de resíduos também são práticas inseridas na gestão de resíduos sólidos (Van de Klundert, Anschutz e Scheinberg, 2001; Lead et al., 2005).

Garcia e Diniz (2016) ressaltam que as políticas públicas de resíduos sólidos, em âmbito federal, estadual e municipal, são representadas, respectivamente, pela Política Nacional de Resíduos Sólidos (Pnrs), Política Estadual de Resíduos Sólidos (Pers) e Política Municipal de Resíduos Sólidos (Pmrs). De acordo com o Ministério do Meio Ambiente - MMA (2016), a Política Nacional dos Resíduos Sólidos inovou nos seguintes quesitos: a) instituição da responsabilidade compartilhada dos geradores de resíduos; b) criação de metas para a eliminação dos lixões; c) patamar de igualdade aos principais países desenvolvidos no que diz respeito ao marco legal; e d) inclusão dos catadores de materiais recicláveis e reutilizáveis, tanto na logística reversa quanto na coleta seletiva.

De acordo com o art. $2^{\circ}$ da Política Nacional de Resíduos Sólidos, além de suas disposições normativas, aplicam-se aos resíduos sólidos as normas estabelecidas pelos órgãos do Sistema Nacional de Meio Ambiente (Sisnama), do Sistema Nacional de Vigilância Sanitária (Snvs), do Sistema Unificado de Atenção à Sanidade Agropecuária (Suasa) e do Sistema Nacional de Metrologia, Normalização e Qualidade Industrial (Sinmetro).

Alguns princípios são defendidos na Pnrs, tais como a cooperação entre as diferentes esferas do poder público, o setor empresarial e os demais segmentos da sociedade, assim como o respeito às diversidades locais e regionais. Dentre seus objetivos e instrumentos, encontram-se a gestão integrada dos resíduos sólidos, a integração dos catadores de materiais reutilizáveis e recicláveis, nas ações que envolvam a responsabilidade compartilhada pelo ciclo de vida dos produtos, e o incentivo à adoção de consórcios ou de outras formas de cooperação entre os entes federados, com vistas à elevação das escalas de aproveitamento e à redução dos custos envolvidos (Brasil, 2010).

As Políticas Nacional e Estadual de Resíduos Sólidos e a Lei $\mathrm{n}^{\circ}$ 11.445/07 cobram dos municípios, ações que permitam a disposição de meios para incrementar a limpeza urbana e o manejo dos resíduos sólidos, incluindo a coleta, o transporte, o transbordo, o tratamento e a destinação final do lixo doméstico e originário da varrição e limpeza de logradouros e vias públicas (Brasil, 2007). Nos termos previstos pela legislação federal, exige-se a elaboração de plano municipal de gestão integrada de resíduos sólidos para que os municípios tenham acesso a recursos da União, ou por ela controlados, destinados a empreendimentos e serviços relacionados à limpeza urbana e ao manejo de resíduos sólidos, ou para serem beneficiados por incentivos ou financiamentos de entidades federais de crédito ou fomento para tal finalidade (Brasil, 2010).

De forma equivalente, a legislação estadual exige dos municípios a apresentação de planos de gerenciamento de resíduos urbanos, aprovados pelo órgão ambiental competente, como requisito para a liberação de financiamentos solicitados a instituições públicas. Os recursos financeiros somente poderão ser liberados, após a apresentação da documentação exigida e da licença ambiental expedida pelo órgão estadual (Ceará, 2001).

Revista de Gestão Social e Ambiental - RGSA, São Paulo, v. 12, n. 2, p. 21-38, maio/ago. 2018. 
Cherfem (2015) esclarece que, além da Pnrs, algumas normas federais apontam para a consolidação de marco regulatório que beneficia catadores de resíduos sólidos. Por exemplo, o Decreto $\mathrm{n}^{\circ}$ 5.940/06 obriga as instituições públicas federais a destinarem seus resíduos recicláveis para cooperativas ou associações de catadores. A Lei de Diretrizes Nacionais para o Saneamento Básico (Lei $\mathrm{n}^{\mathrm{o}}$ 11.445/07) permite que as prefeituras contratem diretamente cooperativas e associações de catadores, por meio de dispensa de licitação, para prestarem serviços de coleta seletiva juntamente com os serviços de limpeza urbana.

A Pnrs representa um importante marco para a gestão dos resíduos no Brasil. Demajorovic e Massote (2017) destacam a inclusão de uma série de instrumentos inovadores, tais como a responsabilidade compartilhada, de modo a assegurar a coleta seletiva e a destinação adequada dos resíduos pós-consumo; a exigência de um Acordo Setorial (AS), e a inclusão das cooperativas de catadores como fornecedores de serviços de coleta na cadeia reversa.

Avanços na implantação da Pnrs poderiam ser ampliados. Em 2014, por exemplo, estava prevista a extinção dos "lixões" e a inclusão dos catadores na cadeia reversa dos materiais recicláveis em todos os municípios do país (Brasil, 2010). Contudo, estas metas não foram alcançadas. Segundo Teodósio, Dias e Santos (2016), novos prazos para a efetiva implantação da Pnrs encontram-se em discussão, com metas escalonadas entre 2018 e 2021, de acordo com o porte dos munícipios. Reforça-se, portanto, a necessidade de contabilizar, dotar de transparência e promover controle social mais efetivo da gestão de resíduos sólidos urbanos.

De acordo com Dal Piaz e Ferreira (2011), para estabelecer um exercício e uma prática de gestão participativa, pressupõe-se o desenvolvimento de processos de construção coletiva. No caso dos resíduos sólidos urbanos exige um esforço de abertura, cooperação e integração entre todos os atores envolvidos. Observa-se, no entanto, uma fraca consciência ambiental por parte da sociedade e uma falta de interesse do poder público em operacionalizar políticas capazes de gerenciar adequadamente os resíduos sólidos urbanos.

\subsection{Desafios dos Munícipios para alcançar a conformidade legal}

Em geral, nos municípios brasileiros existem problemas associados com a disponibilidade de recursos financeiros, humanos e tecnológicos para tratar da gestão dos resíduos sólidos (Khan e Ansari, 2010). Castilhos Júnior et al (2006) alertam que a disposição incorreta em lixões ou aterros controlados decorre da baixa capacitação técnico-administrativa dos agentes públicos, da fraca organização dos órgãos ambientais e municipais responsáveis pela coleta e destino final dos resíduos.

Polaz e Teixeira (2009) consideram que, para os municípios de pequeno e médio porte, é urgente a necessidade de ampliar a participação do Poder Público, em diferentes esferas, quanto à implementação de programas para aperfeiçoar as condições e as ferramentas de gestão de resíduos sólidos urbanos. Quanto às políticas públicas, uma das grandes limitações é que os programas de governo são elaborados para um horizonte de curto prazo, em vez de contemplar a escala de tempo da sustentabilidade, ou seja, pensados para várias gerações.

Além da inadequada dotação orçamentária para tratar da questão dos resíduos, observa-se uma incipiente conscientização da população, quanto aos problemas ambientais decorrentes de uma destinação incorreta dos resíduos. O baixo engajamento da população amplia a dificuldade de realizar a coleta seletiva e ocorre uma deterioração ambiental nos locais de descarte não controlados (lixões).

Khan e Ansari (2010) alertam, ainda, que a fraca integração entre os órgãos municipais resulta em uma baixa eficiência operacional. Em geral, os procedimentos operacionais não são adequadamente especificados e a coleta de resíduos não é supervisionada. Os veículos para a coleta dos resíduos não passam por manutenções preventivas e são operados até o limite da sua capacidade produtiva. Paralelamente, os equipamentos não são desenvolvidos para atender as particularidades geográficas de cada município.

Revista de Gestão Social e Ambiental - RGSA, São Paulo, v. 12, n. 2, p. 21-38, maio/ago. 2018. 
No Brasil, ainda prevalece a presença de catadores de resíduos sólidos com idades variadas, trabalhando em lixões a céu aberto e submetidos a doenças ocupacionais (Eskezia et al., 2016). Dias (2012) ressalta que, embora exista uma alta cobertura da coleta de lixo no Brasil, existe uma irrisória cobertura da coleta seletiva e uma baixíssima realização de compostagem, tornando-se preponderante a interlocução do setor empresarial com o setor público e as organizações de catadores para realização da coleta seletiva.

Heyer e Stegmann (2002) reforçam a necessidade de melhorar a fase de coleta dos resíduos sólidos, por meio de um sistema de coleta ininterrupto, além de investir em tecnologia para tratamento dos resíduos sólidos antes da disposição final no aterro sanitário. Os custos com o gerenciamento de resíduos sólidos incluem a coleta, reciclagem e descarte de resíduos sólidos residenciais, comerciais e industriais não perigosos (Bae, 2010). Por exemplo, cerca de $90 \%$ dos custos do tratamento dos resíduos são contabilizados para a mão-de-obra encarregada pela coleta de resíduos.

Levantamentos realizados pelo Sistema Nacional de Informação sobre Saneamento (Snis) mostram que a maioria dos municípios brasileiros não consegue fazer o controle do volume de resíduos gerados. A ausência do uso de técnicas seguras, como a utilização de balanças, sugere que o volume reportado seja divergente da quantidade gerada (Brasil, 2012). Aremu et al. (2012) relatam também uma longa lista de problemas de saúde pública, agravados por uma inadequada gestão de resíduos.

Opp, Osgood Jr. e Rugeley (2014) reforçam a necessidade de entender quais são os fatores associados à capacidade das prefeituras na implantação de políticas públicas de gerenciamento de resíduos. As prefeituras desempenham um papel primordial na regionalização da gestão de resíduos sólidos urbanos. São responsáveis por desenvolver os planos de gestão, coordenar as atividades operacionais e autorizar a construção de aterros sanitários (Okuda e Thomson, 2007). No entanto, existe uma dificuldade em encontrar novas áreas para a adequada disposição de resíduos. No caso de pequenas comunidades rurais, existe também a dificuldade de assegurar recursos financeiros e conhecimentos técnicos necessários para operar os aterros sanitários dentro dos padrões legais.

Okuda e Thomson (2007) destacam que a reciclagem se apresenta como uma alternativa para reduzir a geração de resíduos urbanos e industriais. Trazem o exemplo do Japão que, em 1991, promulgou a Lei de Promoção da Utilização de Materiais Reciclados e outros atos relacionados e permitiu a integração de todos os níveis de governo na gestão de resíduos sólidos urbanos. Como resultado, o país tornou-se um dos líderes mundiais na reciclagem. No caso do Brasil, para suprir as deficiências na gestão de resíduos, esforços devem ser realizados para a formação de uma aliança estratégica entre os diversos atores públicos e a sociedade civil organizada.

Observa-se a necessidade de desenvolver tecnologia para a conversão de resíduos em energia; realizar programas de incentivo à participação ativa dos cidadãos; implantar a estratégia "3R"; desenvolver e financiar a realização de pesquisa para uma adequada gestão e disposição final de resíduos, para a criação de plataformas virtuais de gerenciamento de resíduos sólidos urbanos nos municípios e ampliação da infraestrutura (Pillai e Shah, 2014).

\section{METODOLOGIA}

A pesquisa caracteriza-se como exploratória com a utilização de método quantitativo. Para compor o universo da pesquisa, foi levantada a relação dos municípios do Estado do Ceará, constituindo-se a fonte primária de dados do estudo. $\mathrm{O}$ instrumento de coleta de dados foi desenvolvido no (extinto) Tribunal de Contas dos Municípios do Estado do Ceará (TCM/CE) e aplicado à população dos 184 municípios cearenses, juntamente aos responsáveis pelas secretarias de meio ambiente ou de obras e serviços dos municípios do estado do Ceará.

A coleta das informações foi realizada com suporte em um formulário sobre a destinação final dos resíduos sólidos e o cumprimento de exigências da Lei Federal $n^{\circ}$ 12.305/10 e da Lei 
Estadual $n^{\circ} 13.103 / 01$. A figura 1 apresenta as perguntas que passaram a constituir as variáveis de análise.

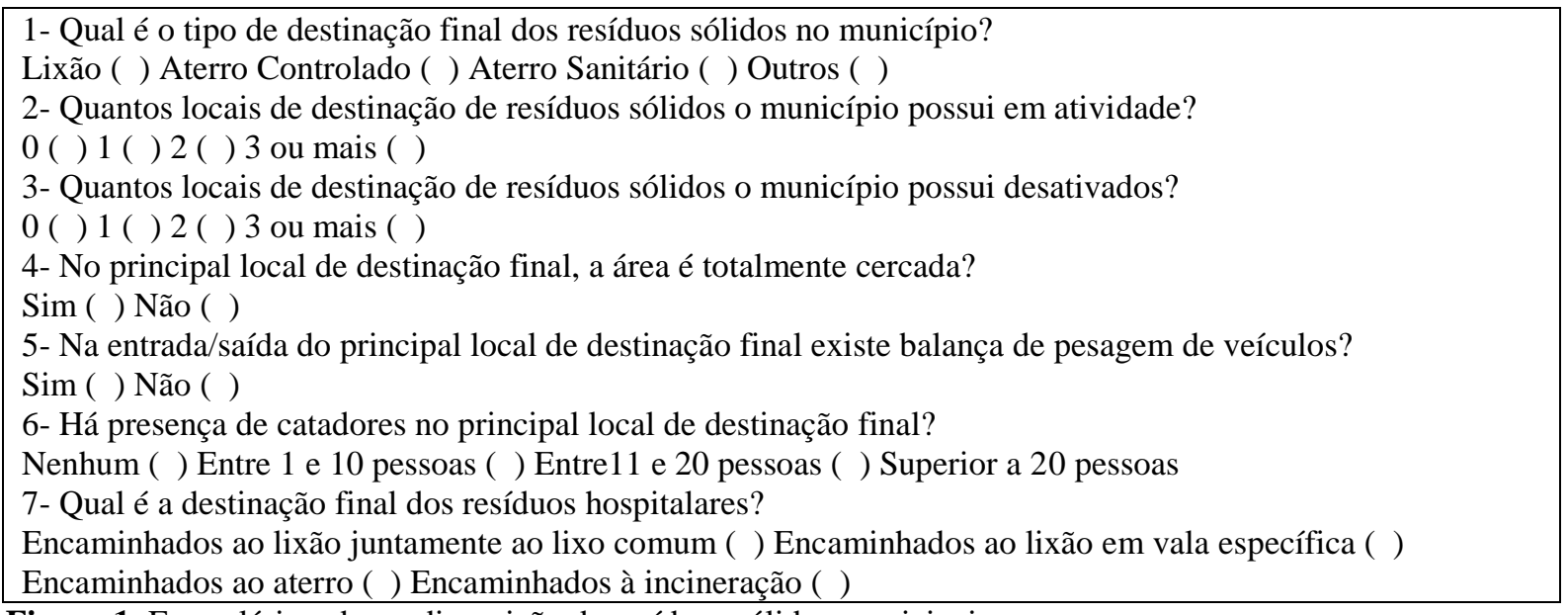

Figura 1. Formulário sobre a disposição de resíduos sólidos municipais

Fonte: Elaboração dos autores com base nas Políticas Nacional e Estadual de Resíduos Sólidos.

O instrumento foi direcionado ao e-mail dos potenciais respondentes, conforme dados cadastrados no TCM/CE, e obteve um índice de retorno de 52,71\%, ou seja, 97 municípios responderam a pesquisa ao longo do mês de janeiro de 2016. A intenção do órgão foi levantar informações para caracterizar o cenário da disposição de resíduos sólidos nos municípios cearenses e o atendimento às exigências legais. $\mathrm{O} T \mathrm{TCM} / \mathrm{CE}$ reconhecia a dificuldade dos gestores municipais quanto à geração de recursos próprios e à dependência de apoio técnico e financeiro de outros entes federativos (federal e estadual).

Os dados coletados refletem, portanto, a realidade dos municípios respondentes no que diz respeito à gestão dos resíduos sólidos. $\mathrm{Na}$ análise dos dados foram adotadas técnicas de estatística descritiva e análise de clusters ou agrupamentos. Essa técnica é utilizada para reunir indivíduos ou objetos em grupos que apresentem características similares, exibindo, portanto, elevada homogeneidade interna (Hair Jr. et al., 2009; Fávero et al., 2009).

O delineamento de uma análise de agrupamentos lida com partição do conjunto de dados para formação de grupos ou clusters. Aplicou-se o método não-hierárquico de agrupamento $K$ Means, comumente utilizado para grandes conjuntos de casos ou observações, assim como a análise da variância ANova por permitir a separação das variáveis do estudo, conforme sua importância no processo de separação dos grupos.

Hair Jr. et al. (2009) afirmam que o objetivo primário da análise de agrupamentos é dividir um conjunto de objetos em dois ou mais grupos com base na similaridade dos objetos em relação a um conjunto de características especificadas. Ao formar esses grupos, foram avaliadas as características das práticas adotadas para o gerenciamento dos resíduos sólidos urbanos nos municípios cearenses. Os dados foram analisados por meio do software estatístico IBM SPSS (versão 21).

\section{RESULTADOS}

A tabela 1 apresenta as frequências absolutas das variáveis não-binárias. A pesquisa evidencia que $89 \%$ dos municípios cearenses destinam os resíduos sólidos ao lixão. Em $81 \%$ dos municípios existe apenas um local em atividade destinado a disposição dos resíduos e no caso de $64 \%$ destes municípios, estes locais ainda se encontram em operação.

No caso dos catadores, observa-se que, em $62 \%$ dos municípios, existem entre um e dez catadores, no entanto, $17 \%$ dos municípios não possuem nenhum catador. Com relação aos resíduos hospitalares, a maioria dos municípios os encaminha a uma vala específica (48\%) ou à incineração

Revista de Gestão Social e Ambiental - RGSA, São Paulo, v. 12, n. 2, p. 21-38, maio/ago. 2018. 
(43\%). Contudo, observa-se que 5\% dos municípios encaminham seus resíduos hospitalares ao lixão juntamente ao lixo comum.

Tabela 1. Distribuição de frequências das variáveis não-binárias

\begin{tabular}{|c|c|c|c|}
\hline Variáveis & Opções de respostas & $\mathbf{N}$ & $\%$ \\
\hline \multirow{3}{*}{ Tipo de destinação } & Lixão & 86 & $89 \%$ \\
\hline & Aterro Controlado & 5 & $5 \%$ \\
\hline & Aterro Sanitário & 6 & $6 \%$ \\
\hline \multirow{4}{*}{$\begin{array}{c}\text { Quantidade de locais em } \\
\text { atividade }\end{array}$} & 0 & 2 & $2 \%$ \\
\hline & 1 & 78 & $81 \%$ \\
\hline & 2 & 13 & $13 \%$ \\
\hline & 3 ou mais & 4 & $4 \%$ \\
\hline \multirow{4}{*}{$\begin{array}{c}\text { Quantidade de locais } \\
\text { desativados }\end{array}$} & 0 & 62 & $64 \%$ \\
\hline & 1 & 26 & $27 \%$ \\
\hline & 2 & 7 & $7 \%$ \\
\hline & 3 ou mais & 2 & $2 \%$ \\
\hline \multirow{4}{*}{ Presença de catadores } & Nenhum & 16 & $17 \%$ \\
\hline & De 1 a 10 catadores & 60 & $62 \%$ \\
\hline & De 11 a 20 catadores & 9 & $9 \%$ \\
\hline & Superior a 20 catadores & 12 & $12 \%$ \\
\hline \multirow{4}{*}{ Resíduos hospitalares } & Encaminhados ao lixão juntamente ao lixo comum & 5 & $5 \%$ \\
\hline & Encaminhados ao lixão em vala específica & 47 & $48 \%$ \\
\hline & Encaminhados ao aterro & 4 & $4 \%$ \\
\hline & Encaminhados à incineração & 41 & $43 \%$ \\
\hline
\end{tabular}

Fonte: Elaboração com base nos dados coletados na pesquisa de campo.

A figura 2 apresenta os resultados em relação as variáveis binárias "Área Cercada" e "Balança de Pesagem". Observa-se, que a maioria dos municípios da pesquisa, totalizando 58\%, possui área totalmente cercada no principal local de destinação final de seus resíduos sólidos. Verificou-se, também, que, na entrada ou saída do principal local de destinação final dos resíduos sólidos, apenas $7 \%$ dos municípios acusaram possuir balança de pesagem de veículo.

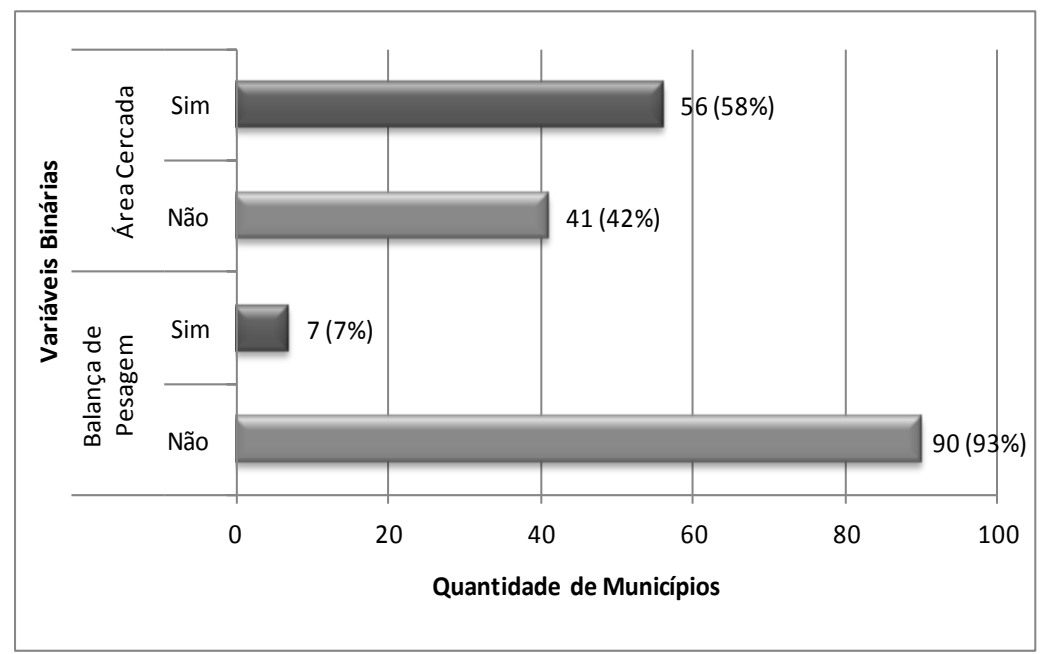

Figura 2. Distribuição de frequências das variáveis "Área Cercada" e "Balança de Pesagem"

Fonte: Elaboração com base nos dados coletados na pesquisa de campo.

Um pressuposto considerado para validar a aplicação da análise de clusters refere-se à ausência de multicolinearidade entre as variáveis selecionadas, para que não existam variáveis altamente correlacionadas entre si. Para confirmar o acolhimento desse pressuposto, efetuou-se a análise de correlação entre as variáveis do estudo com exceção das variáveis binárias. "Área Cercada" e "Balança de Pesagem". Os coeficientes de correlação são apresentados na tabela 2. 
Tabela 2. Matriz de correlação entre as variáveis (Coeficiente de Spearman)

\begin{tabular}{llllll}
\hline & $\begin{array}{l}\text { Tipo de } \\
\text { destinação }\end{array}$ & $\begin{array}{l}\text { Quantidade } \\
\text { locais em } \\
\text { atividade }\end{array}$ & $\begin{array}{l}\text { Quantidade } \\
\text { locais } \\
\text { desativados }\end{array}$ & $\begin{array}{l}\text { Presença de } \\
\text { catadores }\end{array}$ & $\begin{array}{l}\text { Resíduos } \\
\text { hospitalares }\end{array}$ \\
\hline $\begin{array}{l}\text { Tipo de } \\
\text { destinação }\end{array}$ & 1,000 &,- 138 &, 126 &, 157 &, $254^{*}$ \\
$\begin{array}{l}\text { Quantidade de } \\
\text { locais em } \\
\text { atividade }\end{array}$ &,- 138 & 1,000 &,- 019 &,- 003 &,- 175 \\
$\begin{array}{l}\text { Quantidade de } \\
\begin{array}{l}\text { locais } \\
\text { desativados }\end{array}\end{array}$ &, 126 &,- 019 & 1,000 &,- 005 &,$- 275^{* *}$ \\
$\begin{array}{l}\text { Presença de } \\
\text { catadores }\end{array}$ &, 157 &,- 003 &,- 005 & 1,000 &,- 005 \\
$\begin{array}{l}\text { Resíduos } \\
\text { hospitalares }\end{array}$ &, $254^{*}$ &,- 175 &,$- 275^{* *}$ &,- 005 & 1,000 \\
\hline
\end{tabular}

Fonte: Elaboração com base nos dados coletados na pesquisa de campo.

Nota: **. A correlação é significativa ao nível de 5\%. **. A correlação é significativa ao nível de $1 \%$.

Com base na análise da matriz de correlações de Spearman entre as variáveis, pode-se constatar que não existem variáveis com forte grau de correlação entre si $(|0,70 \leq \rho<1|)$. Em razão disso, as cinco variáveis de análise puderam ser mantidas para aplicação da técnica de análise de clusters. Na intenção de validar a construção dos grupos de municípios com base na análise das variáveis, realizou-se a análise de variância (ANova). Ressalta-se que o propósito de utilização da ANova não consistiu em constatar se os grupos eram ou não distintos, mas detectar quais variáveis foram significativas ou não no processo de segregação dos grupos.

De acordo com os resultados apresentados na tabela 3, os valores de significância (Sig.) foram superiores a 0,05 para duas variáveis observadas ("Quantidade de locais em atividade" e "Presença de Catadores"). Dessa forma, observou-se que essas duas variáveis não tinham o poder discriminatório das demais quanto ao processo de separação dos grupos. Portanto, a utilização da análise de variância ANova permitiu classificar as variáveis pela sua importância no processo de segregação.

Tabela 3. Análise de variância - ANova

\begin{tabular}{llllllll}
\hline & Grupo & \multicolumn{2}{l}{ Erro } & F & \multirow{2}{*}{ Sig. } \\
\cline { 2 - 6 } & Quadrado Médio & Df & Quadrado Médio & Df & & \\
\hline $\begin{array}{l}\text { Tipo de destinação } \\
\text { Quantidade de locais }\end{array}$ & 1,164 & 2 &, 252 & 94 & 4,620 &, 012 \\
em atividade &, 361 & 2 &, 283 & 94 & 1,279 &, 283 \\
$\begin{array}{l}\text { Quantidade de locais } \\
\text { desativados }\end{array}$ & 14,309 & 2 &, 229 & 94 & 62,366 &, 000 \\
Presença de catadores & 1,632 & 2 &, 724 & 94 & 2,253 &, 111 \\
Resíduos hospitalares & 46,333 & 2 &, 135 & 94 & 343,057 &, 000 \\
\hline
\end{tabular}

Fonte: Elaboração com base nos dados coletados na pesquisa de campo

As variáveis que apresentam maior valor de $\mathrm{F}$ são aquelas que mais influenciam no processo de separação. Os testes $\mathrm{F}$ devem ser utilizados exclusivamente para finalidades descritivas, visto que os conglomerados foram selecionados para maximizar as diferenças entre as observações em conglomerados distintos. Os níveis de significância verificados não estão corrigidos para essa finalidade e, desse modo, não podem ser interpretados como testes da hipótese de que as médias de conglomerados são iguais.

As variáveis "Tipo de destinação", "Quantidade de locais desativados" e "Resíduos Hospitalares" apresentaram um coeficiente de significância menor que 0,05 (Sig. = 0,000). Portanto, essas três variáveis utilizadas na aplicação da técnica de análise de clusters se mostraram 
mais significantes para a formação dos grupos, ao nível de significância de $5 \%$. A variável "Resíduos Hospitalares" ( $\mathrm{F}=343,057)$ foi a mais significativa para diferenciar os municípios por clusters, seguida das variáveis "Quantidade de locais desativados" ( $F=62,366)$ e "Tipo de destinação" ( $F=4,620)$. Em contrapartida, as variáveis que menos influenciaram a separação dos grupos foram "Presença de Catadores" $(F=2,253)$ e "Quantidade de locais em atividade" $(F=$ 1,279).

Considerando o tipo de algoritmo de agrupamento, optou-se pelo uso do método não hierárquico de agrupamento K-médias ( $\mathrm{K}$-means), comumente utilizado para o agrupamento de conjuntos maiores de casos ou observações. Na figura 3, é exposta a representação gráfica dos valores médios de cada variável. Dessa forma, é possível identificar as diferenças entre os grupos em cada uma das variáveis, a partir dos valores da distância média das observações em relação ao centro do grupo por meio dos distintos clusters. Os resultados dessa solução encontram-se na figura 4, com o agrupamento dos municípios em três clusters (grupos) para sua classificação quanto a características da disposição final de seus resíduos sólidos.

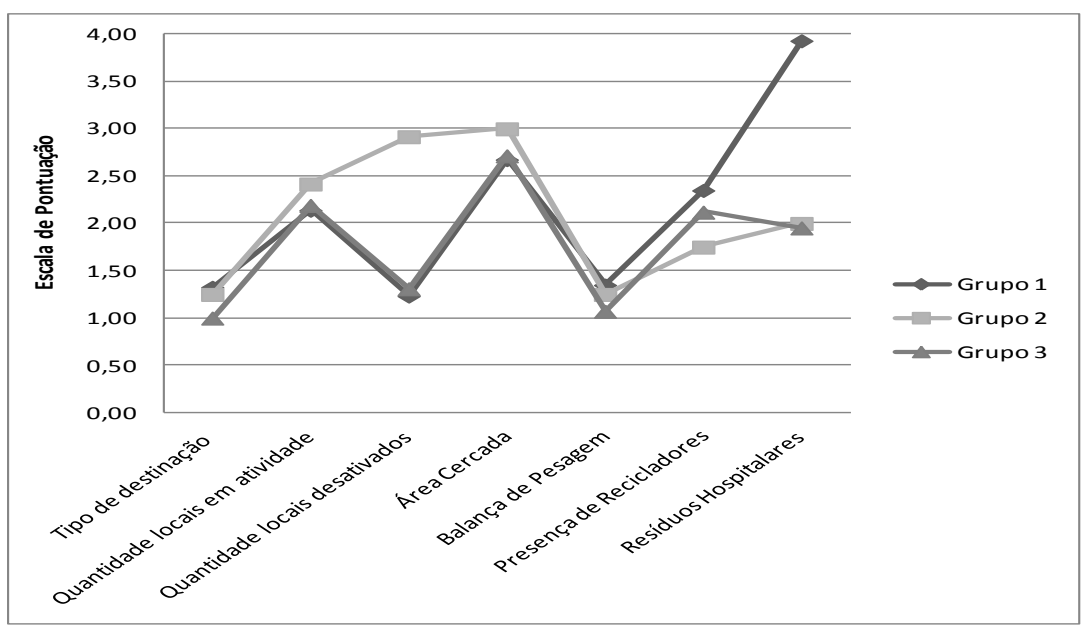

Figura 3. Distribuição média das variáveis por grupo

Fonte: Elaboração com base nos dados coletados na pesquisa de campo.

Com relação à variável "Tipo de destinação", os grupos 1, 2 e 3 se apresentaram de forma bem homogênea, pois, na maioria dos municípios, o tipo de destinação final dos resíduos sólidos é o lixão. No grupo 1, apenas cinco municípios utilizam o aterro controlado (Boa Viagem, Forquilha, Maracanaú, Pacatuba e Ipaporanga), enquanto, no grupo 2, outros seis municípios destinam seus resíduos sólidos para aterros sanitários (Brejo Santo, Caucaia, Horizonte, Fortaleza, Maranguape e Mauriti).

Quanto à variável "Quantidade de locais em atividade", os grupos 1, 2 e 3 também evidenciaram homogeneidade em relação à quantidade de locais de destinação de resíduos sólidos dos municípios em atividade, pois, na maioria, há apenas um local de destinação. Apenas quatro municípios relataram possuir três ou mais locais de destinação de resíduos sólidos em atividade (Deputado Irapuan Pinheiro, Ibicuitinga, Ipueiras e Piquet Carneiro).

No que tange à variável "Quantidade de locais desativados", o grupo 2 se destacou dos demais, pois sete municípios relataram possuir dois locais de destinação de resíduos sólidos desativados (Arneiroz, Cruz, Ibicuitinga, Ipueiras, Jijoca de Jericoacoara, Poranga e Ubajara) e apenas dois municípios, Fortaleza e Jaguaribe, responderam possuir três ou mais locais desativados de destinação dos resíduos sólidos. Esses resultados do grupo 2 divergiram dos demais grupos (1 e 3) que, na sua maioria, não possuem locais desativados de destinação dos resíduos e, quando existem, há no máximo um local desativado no município quanto à destinação dos resíduos sólidos.

Em referência à variável "Presença de Catadores", o grupo 1 se distinguiu principalmente do grupo 2 mostrando uma maior presença de catadores. De forma geral, verificou-se que, na maioria 
dos municípios, a presença de catadores no principal local de destinação final situa-se no intervalo entre uma e dez pessoas. Os resultados permitiram observar que nos municípios com aterros controlados (Boa Viagem, Forquilha, Maracanaú e Pacatuba), com exceção de Ipaporanga, está a maior presença de catadores, superando 20 pessoas no principal local de destinação final dos resíduos sólidos.

\begin{tabular}{|c|c|c|c|}
\hline \multicolumn{4}{|c|}{ GRUPO 1 - 43 MUNICÍPIOS } \\
\hline $\begin{array}{l}\text { - Acaraú } \\
\text { - Assaré } \\
\text { - Beberibe } \\
\text { - Catunda } \\
\text { - Forquilha } \\
\text { - Icó } \\
\text { - Milagres } \\
\text { - Nova Russas } \\
\text { - Parambu } \\
\text { - Saboeiro } \\
\text { - Tarrafas }\end{array}$ & $\begin{array}{l}\text { - Altaneira } \\
\text { - Aurora } \\
\text { - Boa Viagem } \\
\text { - Caucaia } \\
\text { - Groaíras } \\
\text { - Maracanaú } \\
\text { - Miraíma } \\
\text { - Ocara } \\
\text { - Penaforte } \\
\text { - Salitre } \\
\text { - Trairi }\end{array}$ & $\begin{array}{l}\text { - Aracati } \\
\text { - Barbalha } \\
\text { - Brejo Santo } \\
\text { - Crateús } \\
\text { - Guaiuba } \\
\text { - Maranguape } \\
\text { - Monsenhor Tabosa } \\
\text { - Pacatuba } \\
\text { - Pindoretama } \\
\text { - São João do Jaguaribe } \\
\text { - Várzea Alegre }\end{array}$ & $\begin{array}{l}\text { - Aratuba } \\
\text { - Barroquinha } \\
\text { - Carnaubal } \\
\text { - Dep. Irapuan Pinheiro } \\
\text { - Horizonte } \\
\text { - Mauriti } \\
\text { - Morrinhos } \\
\text { - Paraipaba } \\
\text { - Piquet Carneiro } \\
\text { - São Luis do Curu }\end{array}$ \\
\hline \multicolumn{4}{|c|}{ GRUPO 2 - 12 MUNICÍPIOS } \\
\hline $\begin{array}{l}\text { - Arneiroz } \\
\text { - Frecheirinha } \\
\text { - Jaguaribe }\end{array}$ & $\begin{array}{l}\text { - Catarina } \\
\text { - Ibicuitinga } \\
\text { - Jijoca de Jericoacoara }\end{array}$ & $\begin{array}{l}\text { - Cruz } \\
\text { - Ipaporanga } \\
\text { - Poranga }\end{array}$ & $\begin{array}{l}\text { - Fortaleza } \\
\text { - Ipueiras } \\
\text { - Ubajara }\end{array}$ \\
\hline \multicolumn{4}{|c|}{ GRUPO 3 - 42 MUNICÍPIOS } \\
\hline $\begin{array}{l}\text { - Acopiara } \\
\text { - Capistrano } \\
\text { - Cedro } \\
\text { - General Sampaio } \\
\text { - Independência } \\
\text { - Itaiçaba } \\
\text { - Jaguaretama } \\
\text { - Morada Nova } \\
\text { - Porteiras } \\
\text { - Russas } \\
\text { - Varjota }\end{array}$ & $\begin{array}{l}\text { - Ararendá } \\
\text { - Caridade } \\
\text { - Choró } \\
\text { - Graça } \\
\text { - Ipaumirim } \\
\text { - Itapajé } \\
\text { - Jaguaruana } \\
\text { - Mulungu } \\
\text { - Potengi } \\
\text { - Tianguá } \\
\text { - Viçosa do Ceará }\end{array}$ & $\begin{array}{l}\text { - Araripe } \\
\text { - Caririaçu } \\
\text { - Croatá } \\
\text { - Ibiapina } \\
\text { - Iracema } \\
\text { - Itarema } \\
\text { - Limoeiro do Norte } \\
\text { - Palhano } \\
\text { - Quixerê } \\
\text { - Tururu }\end{array}$ & $\begin{array}{l}\text { - Bela Cruz } \\
\text { - Cascavel } \\
\text { - Fortim } \\
\text { - Iguatu } \\
\text { - Irauçuba } \\
\text { - Itatira } \\
\text { - Massapê } \\
\text { - Pereiro } \\
\text { - Reriutaba } \\
\text { - Uruoca }\end{array}$ \\
\hline
\end{tabular}

Figura 4. Classificação dos municípios em grupos

Fonte: Elaboração com base nos dados coletados na pesquisa de campo.

Com relação à variável "Tipo de destinação", os grupos 1, 2 e 3 se apresentaram de forma bem homogênea, pois, na maioria dos municípios, o tipo de destinação final dos resíduos sólidos é o lixão. No grupo 1, apenas cinco municípios utilizam o aterro controlado (Boa Viagem, Forquilha, Maracanaú, Pacatuba e Ipaporanga), enquanto, no grupo 2, outros seis municípios destinam seus resíduos sólidos para aterros sanitários (Brejo Santo, Caucaia, Horizonte, Fortaleza, Maranguape e Mauriti).

Quanto à variável "Quantidade de locais em atividade", os grupos 1, 2 e 3 também evidenciaram homogeneidade em relação à quantidade de locais de destinação de resíduos sólidos dos municípios em atividade, pois, na maioria, há apenas um local de destinação. Apenas quatro municípios relataram possuir três ou mais locais de destinação de resíduos sólidos em atividade (Deputado Irapuan Pinheiro, Ibicuitinga, Ipueiras e Piquet Carneiro).

No que tange à variável "Quantidade de locais desativados", o grupo 2 se destacou dos demais, pois sete municípios relataram possuir dois locais de destinação de resíduos sólidos desativados (Arneiroz, Cruz, Ibicuitinga, Ipueiras, Jijoca de Jericoacoara, Poranga e Ubajara) e apenas dois municípios, Fortaleza e Jaguaribe, responderam possuir três ou mais locais desativados de destinação dos resíduos sólidos. Esses resultados do grupo 2 divergiram dos demais grupos (1 e 3) que, na sua maioria, não possuem locais desativados de destinação dos resíduos e, quando existem, há no máximo um local desativado no município quanto à destinação dos resíduos sólidos. 
Em referência à variável "Presença de Catadores", o grupo 1 se distinguiu principalmente do grupo 2 mostrando uma maior presença de catadores. De forma geral, verificou-se que, na maioria dos municípios, a presença de catadores no principal local de destinação final situa-se no intervalo entre uma e dez pessoas. Os resultados permitiram observar que nos municípios com aterros controlados (Boa Viagem, Forquilha, Maracanaú e Pacatuba), com exceção de Ipaporanga, está a maior presença de catadores, superando 20 pessoas no principal local de destinação final dos resíduos sólidos.

Em relação à “Área Cercada”, observou-se que existem municípios nos grupos 1, 2 e 3 que possuem área totalmente cercada no principal local de destinação final de seus resíduos sólidos e outros que não cercaram a área. Verificou-se, também, que apenas sete municípios pertencentes aos grupos 1 e 2 acusaram possuir "balança de pesagem de veículos" (Acaraú, Caucaia, Maracanaú, Maranguape, Pacatuba, Fortaleza e Itapajé), representados, em sua maioria, pela capital e região metropolitana, ou seja, municípios dotados de maiores recursos orçamentários e financeiros.

No tocante à variável "Resíduos Hospitalares", o grupo 1 foi o que mais se destacou dos demais (2 e 3), pois, na maioria dos municípios desse grupo, o destino final dos resíduos hospitalares é a incineração, à exceção dos municípios de Boa Viagem, Horizonte e Pacatuba, que encaminham seus resíduos hospitalares aos aterros. Em relação ao grupo 2, apenas o município de Fortaleza acusou encaminhar seus resíduos hospitalares à incineração, haja vista que nos grupos 2 e 3, a predominância foi o encaminhamento dos resíduos hospitalares para valas específicas nos lixões.

De maneira geral, foi possível identificar o posicionamento de cada grupo em relação aos demais, ao observar quais seriam os pares de grupos mais próximos ao serem levadas em consideração todas as variáveis de análise. Na tabela 4, são apresentadas as distâncias entre os grupos.

Tabela 4. Distâncias entre centros de grupos finais

\begin{tabular}{llll}
\hline Grupos & 1 & 2 & 3 \\
\hline 1 & & 2,641 & 2,017 \\
2 & 2,641 & & 1,684 \\
3 & 2,017 & 1,684 & \\
\hline
\end{tabular}

Fonte: Elaboração com base nos dados coletados na pesquisa de campo.

Dessa forma, é possível depreender que os resultados do grupo 2 são mais próximos aos do grupo 3 (distância $=1,684$ ), pois apresentaram, em geral, os resultados mais contíguos entre si, exceto pelas variáveis "Quantidade de locais desativados" e "Resíduos Hospitalares". O grupo 1 se distanciou mais do grupo 2 (distância $=2,641$ ) do que em relação ao grupo 3 (distância = 2,017), principalmente devido aos resultados das variáveis "Quantidade de locais desativados" e "Resíduos Hospitalares", ao passo que no grupo 3, sua distância do grupo 1 foi influenciada principalmente pela variável "Resíduos Hospitalares".

\section{DISCUSSÃO}

O trabalho revela a predominância de municípios que não atendem aos requisitos legais estabelecidos nas Políticas Nacional e Estadual de Resíduos Sólidos. A figura 5 apresenta as características encontradas nos grupos de municípios analisados. Pode-se afirmar que no estado do Ceará predomina o grupo 3 caracterizado por uma disposição irresponsável de resíduos sólidos urbanos, com alguns municípios em fase de adequação legal (Grupo 1). O grupo 2 encontra-se em um estágio intermediário, mas que se depreende para a não-conformidade legal.

Os resultados da pesquisa mostram um quadro preocupante, que exige medidas envolvendo a prevenção, reciclagem, tratamento (principalmente dos resíduos hospitalares), disposição final (e.g., cerceamento da área e utilização de balança de pesagem) e recuperação de áreas deterioradas.

Revista de Gestão Social e Ambiental - RGSA, São Paulo, v. 12, n. 2, p. 21-38, maio/ago. 2018. 
De forma semelhante, Barbosa et al. (2016) identificaram a necessidade de adequações às exigências da Política Nacional de Resíduos Sólidos nos municípios de Viçosa (MG). Outro estudo realizado por Crispim et al. (2016), no município de Pombal (PB) confirma a destinação final predominante em vazadouros a céu aberto (lixões), ausência de educação ambiental e ineficiência da gestão municipal quanto ao cumprimento da legislação.

\begin{tabular}{|c|c|c|}
\hline Grupos & Características & Requisitos legais estabelecidos na Pnrs e Pers \\
\hline 1 & $\begin{array}{l}\text { Disposição final de } \\
\text { resíduos sólidos em } \\
\text { fase de adequação } \\
\text { legal }\end{array}$ & $\begin{array}{l}\text { Parte dos municípios encaminha os resíduos sólidos ao aterro sanitário e os } \\
\text { resíduos hospitalares à incineração. } \\
\text { Maior presença de catadores. } \\
\text { Os locais de destinação final de seus resíduos sólidos não são totalmente } \\
\text { cercados. } \\
\text { Necessidade de aquisição de balança de pesagem de veículos. }\end{array}$ \\
\hline 2 & $\begin{array}{l}\text { Disposição final de } \\
\text { resíduos sólidos em } \\
\text { não-conformidade } \\
\text { legal }\end{array}$ & $\begin{array}{l}\text { Municípios destinam os resíduos aos lixões ou aos aterros sanitários. } \\
\text { Maior quantidade de locais ativos e inativos de destinação dos resíduos } \\
\text { sólidos. } \\
\text { Maior quantidade de área totalmente cercada no principal local de } \\
\text { destinação final de seus resíduos sólidos. } \\
\text { Menor presença de catadores. } \\
\text { Parte dos municípios encaminha resíduos hospitalares a valas específicas } \\
\text { nos lixões. }\end{array}$ \\
\hline 3 & $\begin{array}{l}\text { Disposição final } \\
\text { irresponsável de } \\
\text { resíduos sólidos }\end{array}$ & $\begin{array}{l}\text { Municípios destinam os resíduos sólidos para os lixões, os quais não são } \\
\text { totalmente cercados. } \\
\text { Baixa presença de catadores. } \\
\text { Municípios encaminham resíduos hospitalares a valas específicas nos lixões. } \\
\text { Ausência de balança de pesagem de veículos. }\end{array}$ \\
\hline
\end{tabular}

Figura 5. Perfil dos grupos de municípios com relação à disposição final dos resíduos sólidos Fonte: Elaboração com base nos dados coletados na pesquisa de campo

A gestão pública de resíduos sólidos no estado do Ceará requer o aperfeiçoamento e a alocação de significativos recursos humanos, financeiros e tecnológicos. Verificou-se a falta de conhecimento das exigências da legislação por parte de gestores, no que se refere à realização de coleta seletiva, destinação final dos resíduos, realização de consórcios, desconhecimento quanto à elaboração e à realização de ações descritas nos planos plurianuais e ausência de discussão com a sociedade quanto às demandas locais voltadas à gestão dos resíduos sólidos urbanos.

A figura 6 sumariza algumas medidas que podem ser tomadas para alcançar a conformidade legal. Neste sentido, a gestão integrada dos resíduos sólidos urbanos decorre de um esforço mútuo entre os órgãos da administração pública (governos), a iniciativa privada (empresas) e a sociedade. A parceria entre os atores municipais pode gerar a sinergia necessária para superar as principais dificuldades associadas à gestão de resíduos sólidos urbanos, conforme defendem Khan e Ansari (2010).

No âmbito da administração pública, é essencial para a melhoria da gestão dos resíduos sólidos que se invista em fiscalização para coibir, por exemplo, a disposição inadequada de resíduos hospitalares. Também é preciso realizar investimentos contínuos na educação da população, no sentido de reduzir a quantidade de resíduos que entram no sistema de limpeza urbana. Estes desafios também foram relatados por Moraes e Pereira (2012) no manejo dos resíduos em Belo Horizonte $(\mathrm{BH})$. É fundamental que os prefeitos passem a atuar como gestores municipais e avancem além das discussões tradicionais sobre alocação de recursos financeiros. Cabe aos prefeitos o direcionamento das políticas públicas urbanas, a utilização adequada dos meios de comunicação e a promoção da conscientização da população quanto à necessidade de separação dos resíduos sólidos urbanos.

A pesquisa confirma a necessidade de ampliar a participação do poder público, no sentido de conscientizar a comunidade e desenvolver parcerias com as cooperativas de reciclagem. É salutar a integração das cooperativas pelo poder público no sistema de gestão municipal, conforme indicação 
da própria Pnrs, e constatado por Santos et al. (2016), em uma cooperativa de Sorocaba (SP). Devese promover e fiscalizar a adoção de convênios, consórcios ou de outras formas de cooperação entre os entes federados e revisar as regulamentações específicas. Neste sentido, Rodrigues e Ichikawa (2015) reforçam a necessidade de uma dinâmica institucional capaz de tratar adequadamente a questão dos resíduos sólidos urbanos. Tais critérios assemelham-se ao posicionamento de Maiello et al. (2013) quanto ao compartilhamento de competências entre as unidades federativas.

\begin{tabular}{|c|c|}
\hline Elementos & Recomendações \\
\hline Governos & $\begin{array}{l}\text { Aperfeiçoar a fiscalização com a alocação de significativos recursos humanos, } \\
\text { financeiros e tecnológicos } \\
\text { Ampliar a coleta seletiva nos municípios } \\
\text { Realizar consórcios entre os municípios } \\
\text { Criar fóruns de discussão para gerar soluções para a questão dos resíduos sólidos } \\
\text { Ampliar a educação ambiental com ações voltadas para conscientizar a população } \\
\text { Melhorar a infraestrutura de coleta e disposição final de resíduos sólidos } \\
\text { Cumprir as metas estabelecidas nos planos plurianuais } \\
\text { Criar mecanismos de governança para ampliar a participação da sociedade e iniciativa } \\
\text { privada }\end{array}$ \\
\hline Empresas & $\begin{array}{l}\text { Utilizar tecnologias de informação e comunicação para monitoramento dos resíduos } \\
\text { sólidos } \\
\text { Implementar programas de gerenciamentos dos resíduos sólidos não perigosos } \\
\text { (atividades administrativas) e dos resíduos perigosos (hospitalares e ambulatoriais) } \\
\text { Ampliar a evidenciação dos programas de gerenciamento de resíduos sólidos }\end{array}$ \\
\hline Sociedade & $\begin{array}{l}\text { Apoiar e incentivar o trabalho dos catadores } \\
\text { Reduzir a quantidade de resíduos que entra no sistema de limpeza urbana } \\
\text { Fiscalizar o cumprimento dos planos plurianuais }\end{array}$ \\
\hline
\end{tabular}

Figura 6. Medidas para alcance da conformidade legal

Fonte: Elaboração com base nos dados coletados na pesquisa de campo

No âmbito da iniciativa privada, é importante ampliar a utilização de tecnologias de informação e comunicação (TIC) para o monitoramento e difusão de informações sobre resíduos sólidos urbanos. O uso de TIC pode ser um mecanismo efetivo para o cumprimento das metas determinadas na Pnrs. Neste sentido, Klein, Gonçalves-Dias e Jayo (2018) reforçam a importância de práticas de accountability e informação aos cidadãos para ampliar a transparência. De forma semelhante, Vergara e Tchobanoglous (2012) argumentam que os principais desafios da gestão de resíduos sólidos incluem a integração da coleta seletiva de resíduos sólidos com a redução do consumo, além da padronização de procedimentos para a proteção dos catadores e do meio ambiente.

A participação da sociedade também é vital para alcançar a conformidade legal. É fundamental que haja a articulação de arranjos de governança pública e a mobilização do tema no âmbito da sociedade, formando-se uma arena que influencia os atores públicos institucionais e as empresas na tomada de decisões. Silva, Alcântara e Pereira (2016) fizeram uma pesquisa no município de Lavras-MG, e concluíram que a gestão da política de resíduos sólidos, no âmbito municipal, requer o aperfeiçoamento de instrumentos de governança. De forma semelhante, Silva Lima e Da Costa (2016) evidenciaram a importância da governança na gestão de resíduos sólidos urbanos, no município de Curitiba.

As medidas de apoio à organização das cooperativas de catadores envolvem treinamentos e difusão de experiências e boas práticas, além de incentivos à instalação de empresas compradoras de material reciclável, e ao transporte e armazenamento dos materiais recicláveis. Tais iniciativas também interagem com o pensamento de Okuda e Thomson (2007) e Eskezia et al. (2016), no que se refere à redução de geração de resíduos sólidos e incentivo à reciclagem. Santos e GonçalvesDias (2012) afirmam, nessa esteira, que a existência de um expressivo contingente de pessoas que extraem dos resíduos sua principal fonte de sobrevivência acrescenta à problemática dos resíduos 
uma vertente antropológica e sociocultural que, somada aos impactos ambientais e sanitários, requer rigorosa consideração.

A educação ambiental apresenta-se como um fator primordial à maior consciência e participação da sociedade, quanto ao destino final dos resíduos sólidos urbanos. Observa-se a necessidade de estimular parcerias e investimento em educação para a conscientização e sensibilização dos geradores de resíduos, da população e dos gestores das secretarias e órgãos responsáveis pelo meio ambiente na esfera municipal. De acordo com Pillai e Shah (2014), estas ações podem levar a uma maior eficiência no gerenciamento dos resíduos sólidos.

Em geral, essa pesquisa revelou a necessidade de acompanhar as ações das administrações municipais quanto à conformidade legal. $\mathrm{O}$ estado do Ceará apresenta, portanto, um quadro preocupante no tocante às iniciativas efetivas quanto à disposição final adequada dos resíduos sólidos. Outros estudos demonstraram que a situação encontrada no Estado do Ceará se repete em outros municípios brasileiros. A disposição inadequada dos resíduos sólidos demonstra que a irresponsabilidade, do ponto de vista legal, ambiental e sanitário, é predominante, e coloca em risco a saúde pública e os recursos naturais.

\section{CONSIDERAÇÕES FINAIS}

A pesquisa revelou municípios do estado do Ceará com perfis distintos quanto à disposição final dos resíduos sólidos, evidenciando-se, em geral, uma disposição irresponsável. Contrariandose as exigências da legislação aplicada (Políticas Nacional e Estadual de Resíduos Sólidos), percebe-se que o lixão ainda se caracteriza como o principal tipo de destino final de resíduos sólidos, nos municípios cearenses de pequeno porte. Os municípios maiores e com maior poder aquisitivo destinam preferencialmente seus resíduos sólidos para aterros sanitários.

Dentre os desafios da conformidade legal no estado do Ceará, sugere-se a adoção de políticas públicas mais eficazes e uma readequação dos processos de gestão dos resíduos sólidos na esfera municipal. Observa-se, ainda, a urgente necessidade de ampliação da orientação e cobrança dos órgãos de controle, no que diz respeito à elaboração e cumprimento dos planos municipais de gestão integrada de resíduos sólidos. Essa exigência normativa deveria vigorar de forma efetiva desde agosto de 2014, mas não tem sido cobrada. É fundamental repensar a gestão de resíduos sólidos no âmbito municipal, adotando-se esforços no sentido de ampliar a integração dos atores públicos, das empresas e da sociedade em geral. A eliminação dos lixões deve ocorrer não apenas para cumprimento das exigências legais, mas principalmente para a redução dos impactos sociais e ambientais.

Quanto às limitações do estudo, há de se ressaltar que os resultados obtidos são restritos ao estado do Ceará. Os resultados não podem ser extrapolados para representar a realidade dos municípios brasileiros. Outra limitação envolve as técnicas descritivas, pois a análise de clusters não fornece respostas conclusivas sobre o fenômeno estudado, demandando estudos longitudinais que investiguem as características nos agrupamentos 1, 2 e 3, destacados neste estudo.

Esse trabalho, no entanto, apresenta um quadro preocupante e estimula o desenvolvimento de novas pesquisas. É fundamental explorar em profundidade as particularidades dos municípios cearenses e ampliar a pesquisa no contexto nacional. Reforça-se a necessidade de realização de estudos longitudinais, que investiguem mudanças nos comportamentos dos municípios brasileiros e os fatores críticos para alcançar a conformidade legal. A disposição inadequada de resíduos sólidos contribui de forma significativa para a manutenção das desigualdades sociais, constitui uma ameaça à saúde pública, e potencializa a degradação ambiental.

\section{AGRADECIMENTOS}

Ao CNPq, pelo apoio financeiro ao projeto de pesquisa \# 305913/2014-0. Ao Editor Final e aos Revisores Anônimos, por suas contribuições para a melhoria na versão inicial deste artigo.

Revista de Gestão Social e Ambiental - RGSA, São Paulo, v. 12, n. 2, p. 21-38, maio/ago. 2018. 


\section{REFERÊNCIAS}

Abreu, M. C. S., Mesquita, M. D. S. S., \& Silva Filho, J. C. L. (2014). Análise institucional da gestão ambiental pública no semiárido nordestino: o caso do município de Independência-CE. Desenvolvimento em Questão, 12(26), 108-141.

Aremu, A. S., Sule, B. F., Downs, J., \& Mihelcic, J. R. (2012). Framework to determine the optimal spatial location and number of municipal solid waste bins in a developing world urban neighborhood. Journal of Environmental Engineering, 138(6), 645-653.

Bae, S. (2010). Public versus private delivery of municipal solid waste services: the case of North Carolina. Contemporary Economic Policy, 28(3), 414-428.

Barbosa, E. R. G., Sediyama, G. A. S., Reis, A. de O., \& Cezar, L. C. (2016). Adequação de pequenos municípios as exigências da Política Nacional de Resíduos Sólidos: estudo de caso nos municípios de Viçosa-MG e seus limítrofes. Reunir: Revista de Administração, Contabilidade e Sustentabilidade, 6(3), 37-52.

Brasil. (2007). Lei $n^{o} 11.445$, de 5 de janeiro de 2007. Estabelece diretrizes nacionais para o saneamento básico. Diário Oficial da República Federativa do Brasil, Brasília.

Brasil. (2010). Lei $n^{o}$ 12.305, de 2 de agosto de 2010. Institui a Política Nacional de Resíduos Sólidos; altera a Lei no 9.605, de 12 de fevereiro de 1998; e dá outras providências. Diário Oficial da União, 3 de agosto de 2010. Seção 1, Atos do Poder Legislativo. Imprensa Nacional.

Brasil. (2012). Planos de gestão de resíduos sólidos: manual de orientação. Ministério do Meio Ambiente/Iclei - Brasil, Brasília, 156.

Castilhos Jr., A. D., Fernandes, F., Ferreira, J., Jucá, J., Lange, L. C., Gomes, L. P., ... \& Zanta, V. (2006). Gerenciamento de resíduos sólidos urbanos com ênfase na proteção de corpos d'água: prevenção, geração e tratamento de lixiviados de aterros sanitários. Coord.: Armando Castilhos Júnior. Projeto Prosab, 4. Rio de Janeiro: Abes.

Ceará. (2001). Lei $n^{o}$ 13.103, de 24 de Janeiro de 2001. Institui a Política Estadual de Resíduos Sólidos. Diário Oficial do Estado, 5 de fevereiro de 2001.

Cherfem, C. (2015). A coleta seletiva e as contradições para a inclusão de catadoras e catadores de materiais recicláveis: construção de indicadores sociais. Mercado de trabalho: conjuntura e análise. Brasília: Ipea, 89-98.

Crispim, D. L., Fernandes, J. S., Andrade, S. O. de., Sousa, E. P. de., \& Sales, J. C. F. de. (2016). Gestão de resíduos sólidos urbanos: um estudo de caso em uma escola pública no município de Pombal-PB. Revista Verde de Agroecologia e Desenvolvimento Sustentável, 11(1), 1-7.

Dal Piaz, J. F., \& Ferreira, G. M. V. (2011). Gestão dos resíduos sólidos domiciliares urbanos: o caso do município de Marau-RS. Revista de Gestão Social e Ambiental, 5(1), 33-47.

Demajorovic, J., \& Massote, B. (2017). Acordo setorial de embalagem: avaliação à luz da responsabilidade estendida do produtor. RAE-Revista de Administração de Empresas, 57(5), 470482. 
Dias, S. G. (2012). O desafio da gestão de resíduos sólidos urbanos. GV-executivo, 11(1), 16-20.

Eskezia, D., Aderaw, Z., Ahmed, K. Y., \& Tadese, F. (2016). Prevalence and associated factors of occupational injuries among municipal solid waste collectors in four zones of Amhara region, Northwest Ethiopia. BMC Public Health, 16(1), 862.

Fávero, L., Belfiore, P., Silva, F., \& Cham, B. (2009). Análise de dados: modelagem multivariada para tomada de decisão. São Paulo: Campus.

Garcia, E. A. R., \& Diniz, G. M. (2016). Gestão de resíduos sólidos: um estudo sobre a coleta e destinação na esfera municipal. Revista do Tribunal de Contas do Estado de Minas Gerais, 34(1), 53-71.

Giesta, L. C. (2013). Educação ambiental e gestão ambiental no ativo Mossoró da unidade RN/CE da Petrobras. Revista Eletrônica de Administração, 19(2), 453-484.

Gouveia, N. (2012). Resíduos sólidos urbanos: impactos socioambientais e perspectiva de manejo sustentável com inclusão social. Ciência \& Saúde Coletiva, 17, 1503-1510.

Hair, J. F., Black, W. C., Babin, B. J., Anderson, R. E., \& Tatham, R. L. (2009). Análise multivariada de dados. Bookman Editora.

Heyer, K. U., \& Stegmann, R. (2002). Landfill management: leachate generation, collection, treatment and costs. Leachte Management, 1-23.

Jucá, J. F. T., Lima, J., Mariano, M., Firmo, A., Lima, D., Lucena, L., ... \& Reichert, G. (2014). Análise das diversas tecnologias de tratamento e disposição final de resíduos sólidos urbanos no Brasil, Europa, Estados Unidos e Japão. Jaboatão dos Guararapes: Grupo de Resíduos SólidosUfpe.

Khan, M. A., \& Ansari, I. Z. (2010). Municipal solid waste management in India: a case study of Aligarh city. Pranjana: The Journal of Management Awareness, 13(2), 92-104.

Klein, F. B., Gonçalves-Dias, S. L. F., \& Jayo, M. (2018). Gestão de resíduos sólidos urbanos nos municípios da Bacia Hidrográfica do Alto Tietê: uma análise sobre o uso de TIC no acesso à informação governamental. Revista Brasileira de Gestão Urbana, 10(1).

Lead, C., Adedipe, N. O., Sridhar, M. K. C., \& Verma, M. (2005). Waste management, processing, and detoxification. Ecosystems and Human Well-being: Policy Responses, 313-334.

Maiello, A., Christovão, A. C., Britto, A. L. N. de P., \& Frey, M. (2013). Public participation for urban sustainability: investigating relations among citizens, the environment and institutions-an ethnographic study. Local Environment, 18(2), 167-183.

MMA. Ministério do Meio Ambiente. (2016). Sinir - Sistema Nacional de Informações sobre a Gestão dos Resíduos Sólidos. Recuperado em: 11 fev.2016, de: <http://sinir.gov.br/web/guest/logistica-reversa>.

Moraes, R. O., \& Pereira, P. M. S. (2012). O programa de manejo diferenciado e reciclagem de resíduos da prefeitura de Belo Horizonte. Revista de Gestão Social e Ambiental, 6(1), 117-126. 
Okuda, I., \& Thomson, V. E. (2007). Regionalization of municipal solid waste management in Japan: balancing the proximity principle with economic efficiency. Environmental Management, 40(1), 12-19.

Opp, S. M., Osgood Jr, J. L., \& Rugeley, C. R. (2014). Explaining the adoption and implementation of local environmental policies in the United States. Journal of Urban Affairs, 36(5), 854-875.

Pillai, R., \& Shah, R. (2014). Municipal solid waste management: current practices and futuristic approach. SCMS Journal of Indian Management, 11(4), 72-78.

Polaz, C. N. M., \& Teixeira, B. A. D. N. (2009). Indicadores de sustentabilidade para a gestão municipal de resíduos sólidos urbanos: um estudo para São Carlos (SP). Revista Engenharia Sanitária e Ambiental, 14(3), 411-420.

Rodrigues, F. S., \& Ichikawa, E. Y. (2015). O cotidiano de um catador de material reciclável: a cidade sob o olhar do homem ordinário. Revista de Gestão Social e Ambiental, 9(1), 97-112.

Santos, F. F., Fontes, A. R. M., da Silva Moris, V. A., \& de Souza, R. L. R. (2016). Atores da cadeia de reciclagem: influência e impactos na atividade de triagem de materiais em uma cooperativa de Sorocaba-SP. Revista de Gestão Social e Ambiental, 10(3), 85-101.

Santos, M. C. L. D., \& Gonçalves-Dias, S. L. F. (2012). Resíduos sólidos urbanos e seus impactos socioambientais. São Paulo, IEE-USP.

Silva, É. A. F., Alcântara, V. de C., \& Pereira, J. R. (2016). Governança e esfera pública sobre resíduos sólidos urbanos no âmbito municipal. Administração Pública e Gestão Social, 8(3), 137146.

Silva Lima, C., \& da Costa, A. J. S. T. (2016). A importância da educação ambiental para o sistema de coleta seletiva: um estudo de caso em Curitiba. Revista Geográfica Acadêmica, 10(2), 129-137.

Teodósio, A. S., Dias, S. F., \& Santos, M. C. L. D. (2016). Procrastinação da política nacional de resíduos sólidos: catadores, governos e empresas na governança urbana. Ciência e Cultura, 68(4), 30-33.

Van de Klundert, A., Anschütz, J., \& Scheinberg, A. (2001). Integrated sustainable waste management: the concept. Tools for decision-makers. Experiences from the urban waste expertise programme (1995-2001), 1-44.

Vergara, S. E., \& Tchobanoglous, G. (2012). Municipal solid waste and the environment: a global perspective. Annual Review of Environment and Resources, 37, 277-309. 
Data da submissão: 13/06/2017

Data de aceite: 01/02/2018 